International Journal of Engineering \& Technology, $7(2.32)(2018) 143-146$
International Journal of Engineering \& Technology
WPC
Website www.sciencepubco.com/index.php/IJET
Research paper

\title{
Application of Gray Relation Analysis for Multi-Response Optimization of Plasma Heat Assisted Turning Performance
}

\author{
Thella Babu Rao ${ }^{1 *}$, Venu Pilli ${ }^{2}$, Nallamotu Revanth Sai Venkat ${ }^{2}$, Nagandla Pavan ${ }^{2}$, Thalari Shiva Ram ${ }^{2}$ \\ ${ }^{1 *}$ Associate Professor, Department Of Mechanical Engineering, K L E F, Guntur, India. \\ ${ }_{2}^{2}$ students, Department Of Mechanical Engineering, $K L E F$, Guntur, India. \\ *Corresponding Author E-Mail: Thellababurao@Gmail.Com
}

\begin{abstract}
This paper presents optimization of plasma heat assisted turning process for machining hardened EN24 die steel (53HRC) by using gray relational analysis. Flank wear and surface roughness ( Ra) are experimentally measured as the process performance characteristics under varying conditions of preheating temperature, cutting speed and cutting length. The plasma heating approach was implemented to preheat the workpiece. The machining experiments were conducted according to the L16 design of experiments. Since the chosen machining performance indicators are found with confliction for the chosen process variables, the problem is treated as multi-response optimization problem to minimize the tool wear and surface roughness simultaneously. Therefore, the problem was solved by implementing the gray relational analysis and the derived optimal machining conditions were analysed and reported.
\end{abstract}

Keywords: Plasma heat assisted turning, flank wear, surface roughness, EN24 die steel, Gray relational analysis.

\section{Introduction}

The machining process efficiency can be achieved by optimizing the process parameters and process responses. This machining optimization involves reduction of machining costs and standardization in product quality. Without any technique, it is very hard for any operator to adjust the process parameters and conditions for getting optimal responses. There are many complications in optimizing any machining process, they include optimizing in terms of cost, workpiece, tools, safety, time, etc. The important responses in machining are higher surface finish, lower tool wear, higher metal removal rate, less machining time, etc. Gray relational analysis is one such technique, which gives optimal parameters with respect to experiment. Optimal responses, optimal level of process parameters and significant order of process parameters on process responses can be drawn through gray relational analysis. Minitab is a statistical package that can be used for such comparison and optimization.

\section{Literature Review}

Optimization of multi responses is great requirement to produce precision products. In this context, many authors proposed their work in optimization. Ozler et al. [1] with factorial regression method developed a correlation for tool life with surface temperature, feed rate, depth of cut and cutting speed as influencing factors during turning heated austenitic manganese steel with sintered carbide tool. Masood et al. [2] resulted that laser assistance in turning high chromium white cast iron causes shearing in workpiece causes a decrement of $24 \%$ of cutting forces and $22 \%$ decrement in feed forces along with good surface finish when com- pared with dry traditional machining. Martin et al. [3] employed Selective Laser Melting for microstructural characterization of hot work H13 tool steel based on XRD and TEM and inter-related the process parameters. Hongtao et al. [4] noticed that cutting forces and specific cutting energy were reduced $20 \%$ during laser assisted machining on AISI-4130 shaft and reported that LAM produces high axial residual stresses than traditional machining. Ranganathan et al. [5] improved the performance of hot machining by gray analysis for multi-response (Ra, MRR, tool life) optimization of hot turning with oxygen-LPG, the significance order of parameters obtained from ANOVA is feed rate, cutting speed and workpiece temperature. Chakradar et al. [6] observed a significant improvement in hot machining performance at optimal parameters found using gray relation analysis from Taguchi $\mathrm{L}_{27}$ orthogonal array design for hot turning on 15-5 PH SS with the results of ANOVA reveals that cutting speed, feed rate and depth of cut as order of significance. Sivaiah et al. [7] found $23 \%$ improvement in the hot turning performance by using Taguchi based gray relation analysis on hot turning parameters while machining Inconel 718. In addition, with ANOVA showed that the order of significance of process parameters as feed rate, cutting speed, and depth of cut, workpiece temperature on process responses tool life, material removal rate and surface roughness.

Tosun et al. [8] optimized milling parameters with MQL lubrication on $7075 \mathrm{Al}$ alloy using Gray relational analysis and found that feed rate, cutting speed, tool material and cooling technique as significant order of process parameters. Abhang et al. [9] used gray relational analysis with factorial design matrix to enhance the parameters in turning for chip thickness and surface roughness, the results revealed that feed rate, cutting speed and tool nose radius as order of significance on process responses. Shreemoy et al. [10] optimized depth of cut, cutting speed and 
feed in dry turning on AISI 304 with gray relational analysis on cutting force, material removal rate and surface roughness with $\mathrm{L}_{27}$ orthogonal array Taguchi design. Srihari et al. [11] optimized cutting force, surface roughness in high speed turning of Inconel 718 varying feed, cutting speed and depth of cut gray relational grades confirmed that increase in the performance at optimal parameters. Sarikavya et al. [12] used cutting fluid, cutting speed and fluid flow rate for multi-response enhancement in minimal quantity lubrication with gray relation analysis and ANOVA is used to predict the order and importance of process parameters. Ramanujam et al. [13] optimized turning parameters on Al-Sic (10p) MMC with Taguchi based experiments with GRA and provide the order of significance of process parameters for each response tool wear, surface roughness and specific power. Tzeng et al. [14] results of GRA showed optimized process parameters in taguchi orthogonal array experiments on SKD11, while ANOVA results indicated that percentage of significance that process variables contributed to each response.

\section{Experimentation}

\subsection{Materials, Experiments and Measurements}

The surface roughness, flank wear are selected as required optimal response. The experiments were conducted on HMT lathe machine with pre fixed plasma setup as shown in Fig. 1. The turning conditions at which experiments performed are mentioned in Table 1 with preheat temperature, cutting speed and length of cut as process variables. Other variable are fixed at constant values such as depth of cut $1 \mathrm{~mm}$, stand of distance of nozzle as $10 \mathrm{~mm}$, etc. Argon is used as both shielding as well as pilot gas.

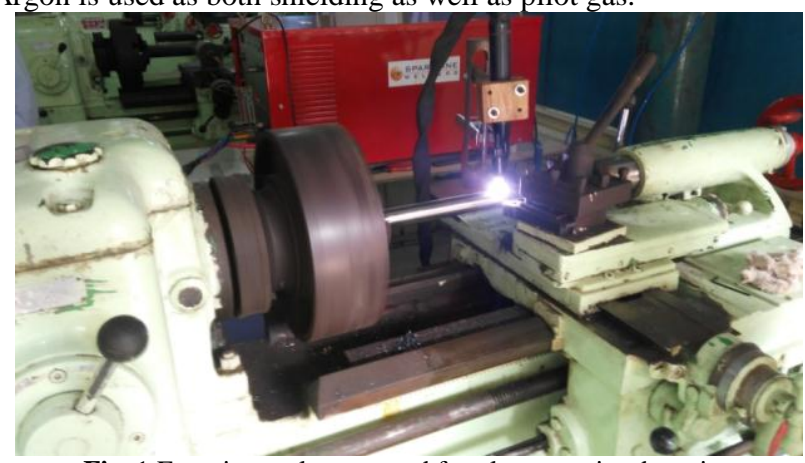

Fig. 1 Experimental setup used for plasma assisted turning

Table 1: Selected list of turning process variables

\begin{tabular}{|c|c|c|c|}
\hline $\begin{array}{c}\text { Level of process } \\
\text { parameters }\end{array}$ & \multicolumn{3}{|c|}{ Process Parameters } \\
\hline & $\begin{array}{c}\text { A } \\
\text { Preheating Tem- } \\
\text { perature }\left({ }^{\circ} \mathrm{C}\right)\end{array}$ & $\begin{array}{c}\text { Cutting Veloc- } \\
\text { ity (m/min) }\end{array}$ & $\begin{array}{c}\text { C } \\
\text { Cutting } \\
\text { Length }(\mathrm{mm})\end{array}$ \\
\hline 1 & 250 & 6 & 225 \\
\hline 2 & 350 & 8 & 450 \\
\hline 3 & 450 & 10 & 675 \\
\hline
\end{tabular}

Plasma heat supplied setup was attached with a chiller to cool the nozzle and machine from overheating. The turning experiment execution was shown in the Fig. 2. The turning was performed on EN24 with $30 \mathrm{~mm}$ diameter. The surface roughness (Ra) of turned workpiece was measured using MITUTOYO make surface roughness tester. And tool makers microscope was used to measure tool wear. Temperature is measured using IR thermometer.

\subsection{Design of Experiments}

Usually to perform the experiments with three different parameters each at three levels requires a total of 27 experiments. However, this is not advisable to do all the experiments as it influences machining costs. Therefore, it is better to choose methods like Taguchi for design of experiments to determine optimal machining parameters. Taguchi acquires responses through orthogonal array and analyse working conditions to find the enhanced process parameters with minimum number of experiments. Three process parameters were used as control variables. With the Taguchi design of experiments, $\mathrm{L}_{16}$ orthogonal array was used.

Table 2: $\mathrm{L}_{16}$ orthogonal array design of experiments

\begin{tabular}{|c|c|c|c|c|c|}
\hline $\begin{array}{c}\text { Experiment } \\
\text { no. }\end{array}$ & $\mathbf{A}$ & $\mathbf{B}$ & $\mathbf{C}$ & $\begin{array}{c}\text { Flank } \\
\text { Wear } \\
(\boldsymbol{\mu m})\end{array}$ & $\begin{array}{c}\text { Surface } \\
\text { Roughness } \\
\mathbf{R}_{\mathbf{a}}(\boldsymbol{\mu m})\end{array}$ \\
\hline 1 & 1 & 1 & 1 & 175 & 1150 \\
\hline 2 & 3 & 1 & 1 & 165 & 1020 \\
\hline 3 & 1 & 3 & 1 & 182 & 1161 \\
\hline 4 & 3 & 3 & 1 & 161 & 1013 \\
\hline 5 & 1 & 1 & 3 & 575 & 1460 \\
\hline 6 & 3 & 1 & 3 & 225 & 1260 \\
\hline 7 & 1 & 3 & 3 & 581 & 1479 \\
\hline 8 & 3 & 3 & 3 & 246 & 1281 \\
\hline 9 & 1 & 2 & 2 & 400 & 1320 \\
\hline 10 & 3 & 2 & 2 & 200 & 1190 \\
\hline 11 & 1 & 2 & 3 & 431 & 1347 \\
\hline 12 & 2 & 1 & 2 & 325 & 1300 \\
\hline 13 & 2 & 3 & 2 & 342 & 1326 \\
\hline 14 & 2 & 2 & 1 & 180 & 1080 \\
\hline 15 & 2 & 2 & 2 & 341 & 1327 \\
\hline 16 & 2 & 2 & 3 & 454 & 1421 \\
\hline
\end{tabular}

\section{Gray Relational Analysis}

To find relation among different factors on multiple responses is complicated and uncertain. Gray relation analysis (GRA) is one such technique from gray system theory to eliminate the ambiguousness in analysing the effects of process variables. The technique is widely accepted due to its ability to get a normalized sequence that is close to the original sequence.

In this processing if the responses are need as higher is better the corresponding normalised sequence equation is eq. (1).

$x_{i}^{*}=\frac{x_{i}^{0}(k)-\min x_{i}^{0}(k)}{\max x_{i}^{0}(k)-\min x_{i}^{0}(k)}$

where $\mathrm{i}=1$ to $\mathrm{m} ; \mathrm{k}=1$ to $\mathrm{n}$. $\mathrm{m}$ is number of experiments and $\mathrm{n}$ is number of process parameters. And if the the responses are need as lower is better the corresponding normalised sequence equation is eq. (2)

$x_{i}{ }^{*}=\frac{\max x_{i}^{0}(k)-x_{i}^{0}(k)}{\max x_{i}^{0}(k)-\min x_{i}^{0}(k)}$

Table 3: The normalized and deviation sequences of process responses \begin{tabular}{|l|c|c|}
\hline Experiment No. & Normalized Sequence & Deviation Sequence \\
\hline
\end{tabular}

\begin{tabular}{|c|c|c|c|c|}
\hline & $\begin{array}{c}\text { Flank } \\
\text { Wear }\end{array}$ & Ra & $\begin{array}{c}\text { Flank } \\
\text { Wear }\end{array}$ & Ra \\
\hline 1 & 0.966 & 0.706 & 0.033 & 0.293 \\
\hline 2 & 0.990 & 0.984 & 0.009 & 0.015 \\
\hline 3 & 0.95 & 0.682 & 0.05 & 0.317 \\
\hline 4 & 1 & 1 & 0 & 0 \\
\hline 5 & 0.014 & 0.040 & 0.985 & 0.959 \\
\hline 6 & 0.847 & 0.469 & 0.152 & 0.530 \\
\hline 7 & 0 & 0 & 1 & 1 \\
\hline 8 & 0.797 & 0.424 & 0.202 & 0.575 \\
\hline 9 & 0.430 & 0.341 & 0.569 & 0.658 \\
\hline 10 & 0.907 & 0.620 & 0.092 & 0.379 \\
\hline 11 & 0.357 & 0.283 & 0.642 & 0.716 \\
\hline 12 & 0.609 & 0.384 & 0.390 & 0.615 \\
\hline 13 & 0.569 & 0.328 & 0.430 & 0.671 \\
\hline 14 & 0.954 & 0.856 & 0.045 & 0.143 \\
\hline 15 & 0.571 & 0.326 & 0.428 & 0.673 \\
\hline 16 & 0.302 & 0.124 & 0.697 & 0.875 \\
\hline
\end{tabular}

Gray relational grade (GRG) is used to get the relevance between two sequences. Equation used to calculate Gray relational coefficient (GRC) is eq. 3. And on averaging GRC with number of variables it gives required Gray relational grade whose corresponding 
equation is (7), where $\gamma_{i}$ correlation level between reference and normalized sequence.

$\xi_{\mathrm{i}}(\mathrm{k})=\frac{\Delta_{\min +\zeta \Delta_{\max }}}{\Delta_{0 \mathrm{i}}+\zeta \Delta_{\max }}$

$\Delta_{0 \mathrm{i}}=\left\|x_{0}^{*}(k)-x_{i}^{*}\right\|$

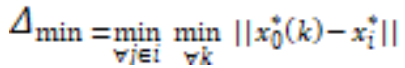

$\Delta_{\min }=\max _{\forall j \in \mathbb{i}} \max _{\forall k}\left\|x_{0}^{*}(k)-x_{i}^{*}\right\|$

$\gamma_{\mathrm{i}=\frac{1}{\mathrm{~m}}} \Sigma_{\mathrm{k}=1}^{\mathrm{n}} \xi_{\mathrm{i}}(k)$

$\gamma_{i=\frac{1}{m}} \sum_{k=1}^{n} w_{k} \xi_{i}(k)$

,$\sum_{k=1}^{n} w_{k}=1$

Table 4: Gray relational coefficients and grades for 16 normalized sequences

\begin{tabular}{|c|c|c|c|c|}
\hline $\begin{array}{c}\text { Experiment } \\
\text { No. }\end{array}$ & \multicolumn{2}{|c|}{$\begin{array}{c}\text { Gray relational coefficient } \\
(\text { GRC })\end{array}$} & $\begin{array}{c}\text { Gray rela- } \\
\text { tional Grade } \\
(\text { GRG })\end{array}$ & Rank \\
\hline & $\begin{array}{c}\text { Flank Wear } \\
(\mu \mathrm{m})\end{array}$ & $\begin{array}{c}\mathrm{R}_{\mathrm{a}} \\
(\mu \mathrm{m})\end{array}$ & & \\
\hline 1 & 0.937 & 0.629 & 0.522 & 4 \\
\hline 2 & 0.981 & 0.970 & 0.650 & 2 \\
\hline 3 & 0.909 & 0.611 & 0.506 & 5 \\
\hline 4 & 1 & 1 & 0.666 & 1 \\
\hline 5 & 0.336 & 0.342 & 0.226 & 15 \\
\hline 6 & 0.766 & 0.485 & 0.417 & 7 \\
\hline 7 & 0.333 & 0.333 & 0.222 & 16 \\
\hline 8 & 0.711 & 0.465 & 0.392 & 8 \\
\hline 9 & 0.467 & 0.431 & 0.299 & 12 \\
\hline 10 & 0.843 & 0.568 & 0.470 & 6 \\
\hline 11 & 0.437 & 0.410 & 0.282 & 13 \\
\hline 12 & 0.561 & 0.448 & 0.336 & 9 \\
\hline 13 & 0.537 & 0.426 & 0.3212 & 11 \\
\hline 14 & 0.917 & 0.776 & 0.564 & 3 \\
\hline 15 & 0.538 & 0.425 & 0.3214 & 10 \\
\hline 16 & 0.417 & 0.363 & 0.260 & 14 \\
\hline
\end{tabular}

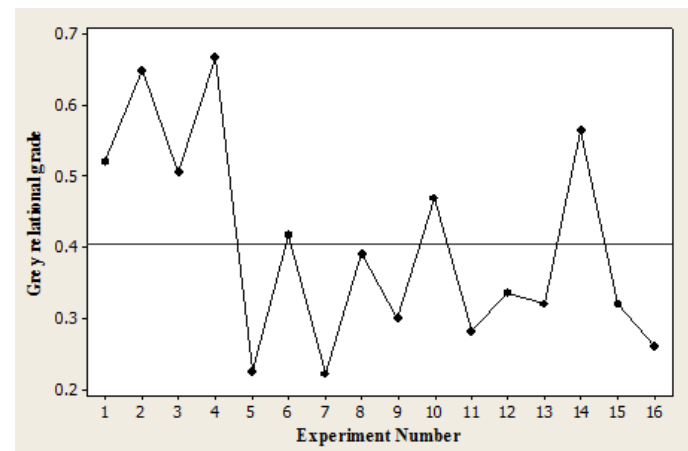

Fig. 3 Gray relational grades for each experiment

\section{Results \& Discussion}

In turning operations, minimum surface roughness, flank wear are part of responses that indicate the performance as better. Gray relation analysis is used for data management. As plasma, assisted turning is selected to minimize surface roughness, flank wear both the responses are chosen as lower is better in gray analysis. So the second equation is used for every experiment to calculate the normalized sequences, the computational results are tabulated as shown in table 3 along with the deviation sequence.

And in the calculation of gray relational coefficient (GRC) for every experiment according to the equation 3 with coefficient $\zeta$ value as 0.5 , along with this gray relational grades (GRG) are calculated which is sum of gray relational coefficient of an experiment divide by number of variable, and tabulated as shown in table 4. As per the grade, ranks were given to every experiment. With the ranks, it is observed that the $4^{\text {th }}$ experiment is the run with optimal turning parameters to get minimum flank wear and surface roughness.

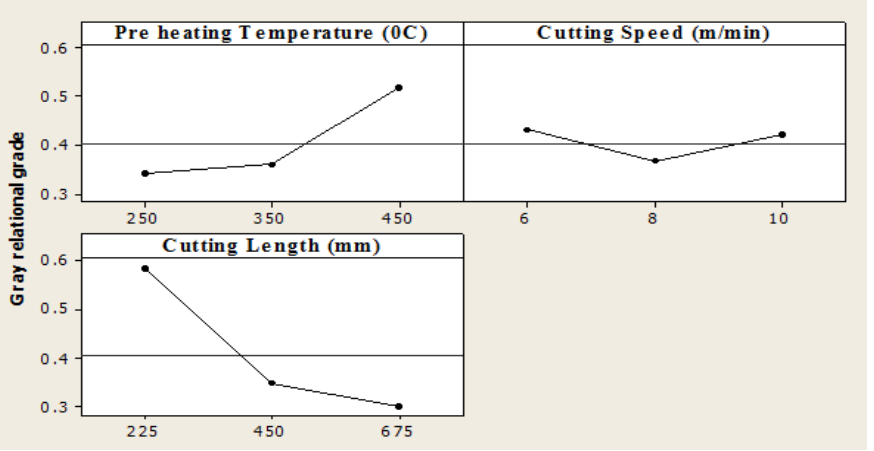

Fig. 4 Effect of turning control variable levels on multi performance

Until now GRG is calculate for experimental runs. Now along with determination of optimal plasma assisted turning parameters for the required responses flank wear, surface roughness. The Taguchi response table method for calculating GRG for levels of turning parameters. The calculation of GRG for each level of turning parameter is the average of GRG for every level, the computed GRG valued for every level of turning parameter was displayed in table 5. The higher the value of GRG indicates that normalized sequence is in good agreement with reference sequence. This means GRG values represents good performance. Table 5 gives the optimal responses flank wear and surface roughness were obtained with preheating temperature of $450{ }^{\circ} \mathrm{C}$, Cutting speed of 6 $\mathrm{m} / \mathrm{min}$ and cutting length of $225 \mathrm{~mm}$. This can be mentioned in short as A3, B1, C1. The effect of turning responses due to each process parameters individually was shown in Fig. 4. Where the highest value corresponding to each process parameter indicates the parameter value at which low flank wear and good surface finish can be produced with respect to individual parameter.

Table 5: The gray relational grade response table

\begin{tabular}{|c|c|c|c|c|}
\hline $\begin{array}{c}\text { Turning parame- } \\
\text { ters }\end{array}$ & \multicolumn{3}{|c|}{ Mean gray relational grade by factor } & $\begin{array}{c}\text { Max - } \\
\text { level }\end{array}$ \\
\hline & Level (1) & Level (2) & Level (3) & \\
\hline A & 0.3434 & 0.3608 & $\mathbf{0 . 5 1 9 5}$ & 0.1760 \\
\hline B & $\mathbf{0 . 4 8 0 5}$ & 0.3665 & 0.4218 & 0.1139 \\
\hline C & $\mathbf{0 . 5 8 2 2}$ & 0.3499 & 0.3002 & 0.2820 \\
\hline
\end{tabular}

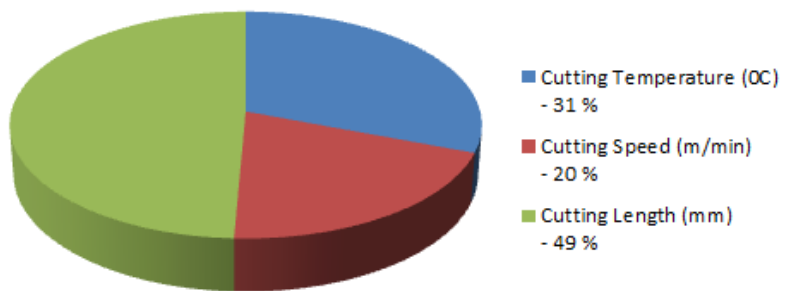

Fig. 5 Pie graph on amount of significance on process responses

The deviation between maximum and minimum value of GRG for each parameter which indicates the effectiveness of each parameter on the process responses. The corresponding values are 0.176097 for preheat temperature. 0.116964 for cutting speed and 0.282022 for cutting length is mentioned in table 5 and shown in the pie graph Fig. 5. The comparison of Max - Min indicates that cutting length is most significant factor on process responses. And the order of significance can be given from table 5 as cutting length: 0.2822022 > Preheat temperature: 0.176097 , Cutting velocity: 0.116964 . It can be interrupted that Cutting length is most significant and cutting velocity is least significant. So considering these parameters and procedure any process can be optimized to reduce machining costs, time, etc. 


\section{Conclusion}

In order to optimize the plasma assisted turning parameters gray relational analysis with Taguchi response table method was performed for each level of performance factor. Minimum flank wear and surface roughness are marked as objectives. Through this cutting length, preheat temperature and cutting speed as order of significant factors influencing output responses. The optimal experiment was found with largest GRG grade. From the overall investigation, gray relational analysis is skilful in optimizing the process responses at multi quality requirement.

\section{References}

[1] L. Ozler, A. Inan, C. Ozel, "Theoretical and experimental determination of tool life in hot machining of austenitic manganese steel", International Journal of Machine Tools \& Manufacture, ELSEVIER, 163-172, 2001.

[2] S. H. Masood, Kelly Armitage, Milan Brandt, "An experimenta study of laser-assisted machining of hard-to-wear white cast iron", International Journal of Machine Tools \& Manufacture, ELSEVIER, 450-456, 2011.

[3] Martin Joachim Holzweissig, Alexander Taube, Florian Brenne, Mirko Schaper and Thomas Niendorf, "Microstructural Characterization and Mechanical Performance of Hot Work Too Steel Processed by Selective Laser Melting", The Minerals, Metals \& Materials Society and ASM International, DOI: 10.1007/s11663 014-0267-9, 2015.

[4] Hongato Ding, Yung C. Shin, "Laser-assisted machining of hardened steel parts with surface integrity analysis", International Journal of Machine Tools \& Manufacture, ELSEVIER, 106-114, 2010 .

[5] S. Ranganathan \& T. Senthilvelan, "Multi-response optimization of machining parameters in hot turning using gray analysis", Int. J. Adv. Manuf. Technol, 56:455-462, DOI:10.1007/s00170-01131985-5, 2011

[6] Venkatesh Ganta, D. Chakradar, "Multi objective optimization of hot machining of $15-5 \mathrm{PH}$ stainless steel using gray relation analysis", ELSEVIER, 1810-1818, 2014.

[7] Venkatesh G, Sivaiah P, Chakradhar D, "Optimization of Hot Turning Parameters by using Taguchi based Gray Relation Analysis", International Journal of Engineering Research, ISSN:2319-6890, 2016.

[8] Nihat Tosun, Hasin Phitil, "Gray relational analysis of performance characteristics in MQL milling of $7075 \mathrm{Al}$ alloy", Int J. Adv. Manuf. Technol, 46: 509-515, DOI: 10.1007/s00170-0092118-4, 2010

[9] L. B. Abhang \& M. Hameedullah, "Determintion of optimum parameters for multi-performance characteristics in turning by using gray relational analysis", Int. J. Adv. Manuf. Technol, DOI: 10.1007/s00170-011-3857-6, 2012.

[10] Shreemoy Kumar Nayak, Jatin Kumar Patro, Shailesh Dewangan, Soumya Gangopadhyay, "Multi-Objective of machining Parameters During Dry Turning of AISI 304 Austenitic Stainless Steel Using Gray Relational Analysis", Procedia Materials Science, ELSEVIER, 2014.

[11] Raju Shrihari Pawade \& Suhas S. Joshi, "Multi-objective optimization of surface roughness and cutting forces in high-speed turning of Inconel 718 using Taguchi gray relational analysis (TGRA), Int. J. Adv. Manuf. Technol, 56:47-62, DOI:10.1007/s00170-011-3183-z, 2011.

[12] Murat Sarikavya, Abdulkadir Gullu, "Multi-response optimization of minimum quantinty lubrication parameters using Taguchi-based gray relational analysis in turning of difficult-to-cut alloy Hayne", Journal of Cleaner Production, ELSEVIER, 91: 347 357, 2015.

[13] Radhakrishnan Ramanujam, Nambi MuthuKrishnan and Ramlasamy Raju, "Optimization of Cutting Parameters for Turning Al-SiC(10p) MMC using ANOVA and Gray Relational Analysis”, Interanational Journal of Precision Engineering and Manufacturing, Springer, Vol. 12, No. 4, pp-651-656-2011.

[14] Chomg-Jyh Tzeng, Yu-Hsin Linb, Yung-Kuang Yang, MingChang Jengc, "Optimization of turning operations with multiple performance characteristics using Taguchi method and Gray relational analysis", Journal of Materials Processing Technology, ELSEVIER, 209: 2753-2759, 2009. 